Ciência Florestal, Santa Maria, v. 20, n. 3, p. 429-437 jul.-set., 2010

ISSN 0103-9954

\title{
MATURAÇÃO E QUALIDADE FÍSICA DE FRUTOS NA GERMINAÇÃO DOS PIRÊNIOS DE Schefflera morototoni (ARALIACEAE)
}

\author{
MATURATION AND PHYSICAL QUALITY OF FRUITS IN THE GERMINATION OF \\ Schefflera morototoni (ARALIACEAE) PYRENES
}

\author{
Maristela Rosália Anastácio ${ }^{1}$ Denise Garcia de Santana ${ }^{2}$ Roberta Camargos de Oliveira ${ }^{3}$ \\ Marcela Mayumi Babata ${ }^{3}$ Carlos Alberto Alves de Oliveira ${ }^{4}$
}

\begin{abstract}
RESUMO
O objetivo do trabalho foi avaliar a influência do estádio de maturação dos frutos nas características físicas e de germinação de pirênios de Schefflera morototoni submetidos a tratamentos pré-germinativos. Frutos com coloração verde e verde-arroxeada foram coletados de 14 acessos, despolpados em água corrente, descartando-se, após contabilização, os pirênios chochos, com endosperma retraído e oxidado, utilizandose os uniformes (com endosperma esverdeado ocupando toda a cavidade do pirênio). O delineamento experimental foi o inteiramente casualizado em esquema fatorial 2 × 5 (estádios de maturação dos frutos e tratamentos pré-germinativos), com quatro repetições em parcelas contendo 25 pirênios. Verificou-se que, para maior capacidade e velocidade de germinação dos pirênios, os frutos devem ser colhidos quando apresentarem coloração verde-arroxeada, descartando-se aqueles com pirênios chochos, endosperma retraído ou oxidado. A capacidade de germinação dos pirênios com endosperma uniforme varia entre 50 e $60 \%$, com início do processo em cerca de 40 dias após semeadura, se estendendo por até 60 dias em vermiculita. Pirênios despolpados, secos e embebidos em água a $60^{\circ} \mathrm{C}$ por 5 minutos, seguida da embebição em água à temperatura ambiente por 12 horas iniciam o processo de germinação em menor tempo, em relação aos despolpados, secos, escarificados e embebidos por 6 horas. O endocarpo dos frutos é permeável e rígido, no entanto, apresenta abertura natural quando embebido.
\end{abstract}

Palavras-chave: permeabilidade; sementes vazias; tratamentos pré-germinativos.

\begin{abstract}
The objective of this study was to evaluate the influence of the maturation stage of the fruit on the physical characteristics and germination of Schefflera morototoni pyrenes submitted to pre-germination treatments. Fruits with green and purplish green coloration were collected from 14 accesses, pulped in running water, discarding the hollow pyrenes, after counting, together with retracted and oxidized endosperm, and using the uniform pyrenes (with greenish endosperm occupying the whole cavity of the pyrene). The experiment was conducted in a completely randomized design in a $2 \times 5$ factorial scheme (stages of fruit maturation and pre-germination treatments), with four repetitions in parcels containing 25 pyrenes. For greater capacity and germination speed of the pyrenes, fruits should be harvested when they present a purplish green coloration, while discarding those with hollow pyrenes, with retracted or oxidized endosperm. The germination capacity of the pyrenes with uniform endosperm varied between 50 and $60 \%$, with the beginning of the process at about 40 days after planting and continuing for up to 60 days in vermiculite. Pulped pyrenes, dried and
\end{abstract}

1. Bióloga, Mestranda do Programa de Pós-graduação em Agronomia, Instituto de Ciências Agrárias, Universidade Federal de Uberlândia, Av. Amazonas s/n, Caixa Postal 593, CEP 38400-902, Uberlândia (MG). Bolsista CAPES. maristelaanastacio@yahoo.com.br

2. Engenheira Agrônoma, $\mathrm{Dr}^{\mathrm{a}}$., Professora Adjunto do Instituto de Ciências Agrárias, Universidade Federal de Uberlândia, Av. Amazonas s/n, Caixa Postal 593, CEP 38400-902, Uberlândia (MG). dgsantana@umuarama.ufu.br

3. Estudante de Agronomia, Instituto de Ciências Agrárias, Universidade Federal de Uberlândia, Av. Amazonas s/n, Bairro Umuarama, Caixa Postal 593, CEP 38400-902, Uberlândia (MG). robertacamargoss@gmail.com

4. Engenheiro Agrícola, Dr., Professor da Escola Agrotécnica Federal de Uberlândia, Fazenda Sobradinho, Caixa Postal 592, CEP 38400-974, Uberlândia (MG). carlosaao@eafudi.gov.br

Recebido para publicação em 12/03/2009 e aceito em 06/04/2010.

Ci. Fl., v. 20, n. 3, jul.-set., 2010 
Anastácio, M. R. et al.

soaked in water at $60^{\circ} \mathrm{C}$ for 5 minutes, followed by soaking in water at room temperature for 12 hours began the germination process in less time, in relation to those pulped, dried, scarified and soaked for 6 hours. The fruit endocarp is permeable and rigid; however, it presents a natural opening when soaked.

Keywords: permeability; empty seeds; pre-germination treatments.

\section{INTRODUÇÃO}

No Brasil, o gênero Schefflera érepresentado por aproximadamente quarenta espécies (FIASCHI, 2004), sendo o maior da família Araliaceae (WEN et al., 2001). Considerado polifilético (WEN et al., 2001), as espécies do gênero apresentam hábito, sistemas sexuais e caracteres morfológicos variáveis e ampla distribuição geográfica (FIASCHI e PIRANI, 2007), sendo normalmente cultivadas para fins ornamentais (MENEZES et al., 2007).

Entre as espécies do gênero, Schefflera morototoni (Aubl.) Maguire, Steyerm. \& Frodin ocorre em diferentes tipologias florestais, como em florestas altas e densas de terra firme, capoeiras, capoeirões, margens de estradas e savanas em quase todo território brasileiro, exceto nos estados do Piauí e Tocantins (CARVALHO, 2003; OHASHI e LEÃO, 2005). Com distribuição espacial ampla, apresenta baixa frequência de indivíduos nos locais de ocorrência (FRANCO e FERREIRA, 2002; SILVA et al., 2004), entre 14 e 39 indivíduos por ha $^{-1}$ (SILVA et al., 2004; BRAGA e REZENDE, 2007; GIEHL et al., 2007), mesmo com abundante quantidade de frutos e sementes produzidas anualmente (FRANCO e FERREIRA, 2002).

A árvore possui fuste cilíndrico e reto, com ramificações somente no ápice, sendo utilizada para fabricação de pasta celulósica e papel (OHASHI e LEÃO, 2005), além disso, a madeira é de fácil manuseio e acabamento (CARVALHO, 2003).

$\mathrm{Em}$ função do rápido crescimento $\mathrm{e}$ potencialidade silvicultural, a espécie é utilizada para reflorestamento, embora tenha como fator limitante para a produção de mudas a baixa taxa de germinação, possivelmente causada pela rigidez do tegumento ou por problemas relacionados com o embrião (FRANCO e FERREIRA, 2002). Outra dificuldade de propagação se deve à heterogeneidade da maturação, à sazonalidade em relação à produção de frutos, à porcentagem de sementes danificadas por larvas de insetos e às sementes com endosperma retraído e sem embrião (FRANCO e FERREIRA, 2002). Soma-se a isso, a baixa capacidade germinativa das sementes após o armazenamento, dificultando a aquisição de material de propagação para a formação de mudas (LEÃO, 1984). Diante disso, o objetivo do trabalho foi avaliar a influência do estádio de maturação dos frutos nas características físicas e de germinação de pirênios de Schefflera morototoni submetidos a tratamentos pré-germinativos.

\section{MATERIAL E MÉTODOS}

\section{Localização e características da área de estudo}

Entre os meses de março e junho de 2008 foram georreferenciados 14 acessos de Schefflera morototoni localizados na bacia do Rio Araguari no município de Uberlândia e nos distritos de Martinésia e Cruzeiro dos Peixotos, todos no estado de Minas Gerais, com distância de no mínimo, 30 $\mathrm{m}$ entre os acessos. Somente acessos com fuste ereto, sem bifurcações e com abundância de frutos em processo de maturação foram selecionados.

A região da bacia do rio Araguari está coberta por cerrados e cerradões nos interflúvios e florestas ao longo dos vales, topos das colinas muito largos com latossolos de baixa fertilidade. O clima apresenta duas estações bem definidas ao longo do ano: inverno seco de abril a agosto, com temperaturas amenas (média de $20^{\circ} \mathrm{C}$ ), e verão quente e úmido (média de $25^{\circ} \mathrm{C}$ ), estendendo-se de setembro a março e pluviosidade média entre 1.200 a $1.500 \mathrm{~mm} / \mathrm{ano}$ (LIMA et al., 2004).

\section{Espécie estudada}

Schefflera morototoni é uma espécie perenifólia, conhecida popularmente como morototó, mandiocão, caixeta, dentre outros nomes (CARVALHO, 2003; OHASHI e LEÃO, 2005), de fuste cilíndrico, retilíneo ou pouco tortuoso, podendo chegar até $15 \mathrm{~m}$ de comprimento (CARVALHO, 2003). As folhas são compostas, digitadas, com folíolos de face dorsal amareloferrugíneo e face ventral verde brilhante (OHASHI e LEÃO, 2005). As inflorescências são terminais, parciais umbeladas com até 40 flores (FIASHI e PIRANI, 2007). As flores são pequenas, numerosas, de coloração bege-clara, sésseis ou pediceladas e

Ci. Fl., v. 20, n. 3, jul.-set., 2010 
hermafroditas (OHASHI e LEÃO, 2005). Os frutos são do tipo drupa carnosa, contendo geralmente dois pirênios (CARVALHO, 2003; OHASHI e LEÃO, 2005) que botanicamente são as sementes de formato oblongo e achatado, com cerca de $5 \mathrm{~mm}$ no maior comprimento e menos de $1 \mathrm{~mm}$ de espessura; apresenta endosperma; o embrião é diminuto e reto (OHASHI e LEÃO, 2005).

\section{Coleta e beneficiamento}

Várias panículas de um mesmo acesso foram coletadas com podões (tesouras), depois da escalada das árvores que apresentavam alturas superiores a $10 \mathrm{~m}$ de altura. As panículas dos 14 acessos foram coletadas em junho de 2008, quando os frutos apresentavam mudança de coloração entre verde e verde-arroxeado. No beneficiamento, os frutos foram retirados das panículas e separados de acordo com o estádio de maturação (verde e verdearroxeado), homogeneizados e colocados sobre peneira para a remoção da polpa em água corrente e obtenção dos pirênios.

\section{Densidade física dos pirênios e características do endosperma}

Em recipientes plásticos contendo água, foram colocados 500 pirênios provenientes de frutos recém-colhidos na coloração verde e 500 na coloração verde-arroxeada para excluir os pirênios com baixa densidade (chochos). Aqueles que permaneceram no fundo do recipiente foram examinados sob microscópio estereoscópico em função da coloração e uniformidade do endosperma e classificados como: endosperma retraído, deslocado para a extremidade do pirênio; endosperma oxidado, com partes escuras e endosperma uniforme (esverdeado, ocupando toda a cavidade do pirênio). Essa classificação dos pirênios só é possível em sementes recém-colhidas e úmidas, uma vez que após a secagem essas características não são mais visualizadas. Os pirênios com endosperma uniforme foram dispostos sobre papel toalha para a retirada do excesso de água e secos por 12 horas à temperatura ambiente $\left(25^{\circ} \mathrm{C} \pm 1,5^{\circ} \mathrm{C}\right)$.

\section{Curva de embebição e teor de água}

Para verificar a permeabilidade do endocarpo, a curva de embebição, que relaciona a massa dos pirênios $(\mathrm{g})$ e o tempo de embebição (minuto), foi construída com oito repetições de 20 pirênios secos. Inicialmente, foram pesados em balança analítica, colocados sobre papel de filtro umedecido com $10 \mathrm{~mL}$ de água destilada, pesados a cada 30 minutos até a estabilização das massas.

Para os teores de água, foram utilizados pirênios recém-colhidos (secos com papel toalha), provenientes de frutos verdes e verdearroxeados, com oito repetições em parcelas de 20 pirênios. Os pirênios foram acondicionados em cápsulas de alumínio, submetidos à secagem em estufa a $70^{\circ} \mathrm{C}$ até atingirem a massa constante, com teores determinados pela expressão: teor de água - [(MMF - MMS)/MMS]*100 em que: MMF é massa da matéria fresca dos pirênios e MMS é a massa da matéria seca dos pirênios.

\section{Germinação dos pirênios, medidas avaliadas e análise estatística}

Na condução do experimento de germinação, pirênios com endosperma uniforme, dos 14 acessos, foram homogeneizados e distribuídos segundo o delineamento inteiramente casualizado em esquema fatorial $2 \times 5$, sendo o primeiro fator correspondente aos estádios de maturação dos frutos (verde e verdearroxeado) e o segundo fator aos tratamentos prégerminativos, com quatro repetições em parcelas contendo 25 pirênios.

Os tratamentos pré-germinativos constituíram de pirênios despolpados e semeados (1); pirênios despolpados e secos (2); pirênios despolpados, secos e escarificados mecanicamente em toda a extremidade arredondada (3); pirênios despolpados, secos, escarificados mecanicamente (extremidade arredondada) e embebidos em água destilada à temperatura ambiente por 6 horas (4) e pirênios despolpados, secos, embebidos em água a $60^{\circ} \mathrm{C}$ por 5 minutos e posterior embebição em água destilada à temperatura ambiente por 12 horas (5). Nos tratamentos que envolveram pirênios secos, a secagem foi feita à temperatura ambiente $(25 \pm$ $1,5^{\circ} \mathrm{C}$ ) sobre papel toalha por 12 horas e quando escarificados, lavados em água corrente por 12 horas em temperatura ambiente $\left(25 \pm 1,5^{\circ} \mathrm{C}\right)$.

Os pirênios foram dispostos em caixas do tipo gerbox contendo $160 \mathrm{~mL}$ de vermiculita umedecida com $80 \mathrm{~mL}$ de água destilada, mantidos em câmara de germinação (Seedburo Equipment Company modelo MPG-2000), sob luz branca fluorescente contínua, em temperatura variável entre 25 e $27^{\circ} \mathrm{C}$. O critério de germinação adotado 
foi a protrusão da radícula, sendo as avaliações realizadas diariamente. Ao final das leituras, 90 dias após semeadura, foram calculadas as seguintes medidas: tempos inicial, médio e final de germinação, percentual de germinação, velocidade de emergência, coeficiente de variação do tempo, incerteza e índice de sincronização. Expressões matemáticas, autores e interpretações dessas medidas de germinação podem ser consultados em Ranal e Santana (2006). A análise de variância foi aplicada, testando-se pelo " $F$ de Snedecor" os efeitos principais e a interação, seguida pelas comparações múltiplas pelo teste de Tukey a 0,05 de significância para comparações entre os estádios de maturação e entre os tratamentos pré-germinativos.

\section{RESULTADOS E DISCUSSÃO}

Em pirênios de Schefflera morototoni, foram altos os percentuais de endosperma oxidado, acima de 50\%, e menores os percentuais de chochos e com endosperma retraído (Tabela 1). A cumarina, um composto fenólico, foi encontrada na família Araliaceae por Ribeiro e Kaplan (2002), essa substância assim como o ácido clorogênico e seus derivados podem sofrer oxidação, além de inibir a germinação das sementes quando presentes no tegumento (BEWLEY e BLACK, 1994). Para minimizar ou eliminar este efeito negativo sobre a germinação, diversas técnicas foram utilizadas como pré-secagem das sementes em estufa de circulação forçada do ar (VIEIRA et al., 1994), envelhecimento acelerado e armazenamento (LOPES et al., 1998), secagem em câmara seca (MEDEIROS e SILVA, 2001), lavagem em água corrente (SILVA et al., 2005), embebição (NAZÁRIO, 2006) e remoção da mucilagem externa (TOKUHISA et al., 2007). Dessas técnicas, para sementes de morototó foi utilizada a remoção do mesocarpo (parte carnosa), além da secagem em temperatura ambiente $\left(25^{\circ} \mathrm{C}\right)$, lavagem em água corrente e embebição dos pirênios.

Dos frutos formados de Schefflera morototoni, apenas 16,2\% com coloração verdearroxeada e 22,4\% dos verdes apresentaram endosperma uniforme (Tabela 1). Sementes viáveis podem variar de acordo com a época de coleta (FRANCO e FERREIRA, 2002). Tais autores registraram $40 \%$ de sementes aparentemente saudáveis no mês de abril; 35,13\% em junho e o maior percentual, $60 \%$, foi obtido em setembro.

Para testar a viabilidade de sementes de Schefflera morototoni, Martins Netto e Faiad (1995) realizaram o teste de tetrazólio (Cloreto de 2,3,5 Trifenil Tetrazólio) encontrando $68 \%$ de sementes viáveis e também um teste de germinação no qual a germinação não ocorreu. Armelin (2005) também conduziu o teste de tetrazólio para dois experimentos com sementes de Schefflera angustissima (March.) Frodin, sendo que, no primeiro experimento, obteve $17,07 \%$ de sementes viáveis e, no segundo, 13,64\%, porém a germinação não ocorreu em ambos os experimentos.

A curva de embebição dos pirênios originados de frutos verdes indicou que o endocarpo é permeável, com embebição efetiva ocorrendo em 180 minutos (Figura 1). Essa informação também é confirmada por Franco e Ferreira (2002), embora Liegel (1990) tenha considerado que pirênios dessa espécie apresentam endocarpo duro e impermeável. Um indicativo da permeabilidade é o fato de que em experimentos utilizando escarificação química com $\mathrm{H}_{2} \mathrm{SO}_{4}$ e $\mathrm{HCl}$ desenvolvidos por Franco e Ferreira (2002), a germinação não ocorreu, e as sementes escarificadas com ácido sulfúrico ficaram enegrecidas.

Os teores de água dos pirênios recémcolhidos de frutos verdes e verde-arroxeados foram 64,7 e 59,1\% respectivamente. Esses valores diferem

TABELA 1: Percentuais de pirênios chochos, com endosperma retraído, oxidado e uniforme de Schefflera morototoni (Aubl.) Maguire, Steyerm. \& Frodin coletados em fragmentos florestais na bacia do Rio Araguari, MG.

TABLE 1: Percentage of hollow, retracted, oxidized and uniform endosperm of Schefflera morototoni (Aubl.) Maguire, Steyerm. \& Frodin pyrenes harvested in forest fragments in the basin of Araguari River, MG.

\begin{tabular}{l|c|c|c|c}
\hline \multirow{2}{*}{ Estágio de maturação } & Pirênios & \multicolumn{3}{|c}{ Endosperma } \\
\cline { 3 - 5 } & Chochos (\%) & retraído (\%) & oxidado (\%) & uniforme (\%) \\
\hline Frutos verdes & 4,8 & 5,6 & 67,2 & 22,4 \\
Frutos verde-arroxeados & 14,4 & 17,4 & 51,8 & 16,2 \\
\hline
\end{tabular}

Ci. Fl., v. 20, n. 3, jul.-set., 2010 


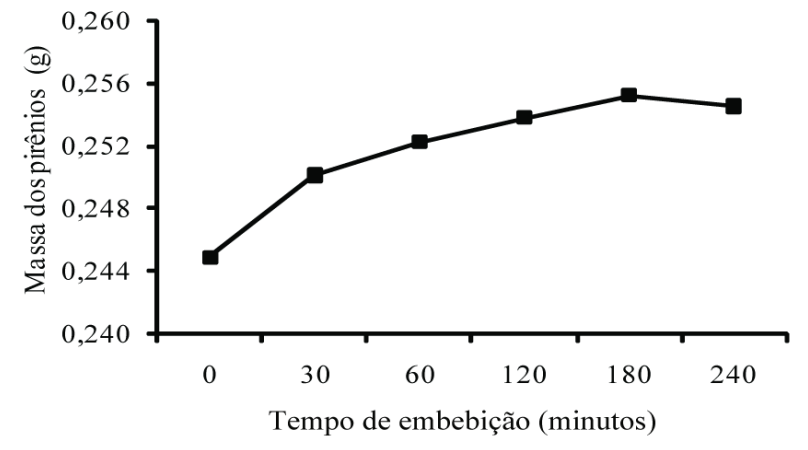

FIGURA 1: Massa dos pirênios (g) de Schefflera morototoni (Aubl.) Maguire, Steyerm. \& Frodin coletados em fragmentos florestais na bacia do Rio Araguari, MG em relação ao tempo de embebição (minutos).

FIGURE 1: Mass (g) of Schefflera morototoni (Aubl.) Maguire, Steyerm. \& Frodin pyrenes harvested in forest fragments in the basin of Araguari River, MG in relation to soaking time (minute). dos encontrados por Leão (1984) que registrou teor de água de 9,2\% para sementes secas à sombra por 24 horas. Possivelmente o menor teor tenha sido em função do maior tempo de secagem das sementes utilizado pelo autor.

Pirênios provenientes de frutos verdearroxeados apresentaram menor tempo inicial e médio de germinação (38 e 48 dias respectivamente; Tabela 2) em relação aos provenientes de frutos verdes, que foram mais lentos (tempos inicial e médio de 42 e 51 dias respectivamente), independente dos tratamentos pré-germinativos. Embora tenham iniciado a germinação em tempos estatisticamente diferentes, pirênios de frutos nos dois estádios de maturação estenderam o processo de germinação por mais de dois meses.

O percentual de germinação dos pirênios de frutos verde-arroxeados foi cerca de $22 \%$ maior do que o registrado para frutos verdes (63 e $41 \%$ respectivamente) (Tabela 3). Mesmo com germinação superior a $50 \%$, valores de $V E$ de 0,20 e 0,33 pirênio dia $^{-1}$ para frutos verdes e

TABELA 2: Tempos de germinação de pirênios de Schefflera morototoni (Aubl.) Maguire, Steyerm. \& Frodin coletados em diferentes estádios de maturação em fragmentos florestais na bacia do Rio Araguari, MG e submetidos a tratamentos pré-germinativos ${ }^{(1)}$.

TABLE 2: $\quad$ Times of germination of Schefflera morototoni (Aubl.) Maguire, Steyerm. \& Frodin pyrenes harvested in different stages of fruit maturation in forest fragments in the basin of Araguari River, MG and submitted to pre-germination treatments.

\begin{tabular}{l|c|c|c}
\hline \multicolumn{1}{c|}{ Fatores } & \multicolumn{3}{c}{ Tempo de germinação ${ }^{1}$} \\
\hline Estágio de maturação & $t_{\mathrm{o}}$ (dia) & $t_{\mathrm{f}}$ (dia) & $\bar{t}$ (dia) \\
\hline Frutos verdes & $41,75 \mathrm{~b}$ & $65,50 \mathrm{a}$ & $51,41 \mathrm{~b}$ \\
Frutos verde-arroxeados & $38,20 \mathrm{a}$ & $63,05 \mathrm{a}$ & $48,40 \mathrm{a}$ \\
\hline$D M S(0,05)$ & 2,71 & 5,80 & 1,74 \\
\hline Tratamentos pré-germinativos $^{2}$ & $t_{\mathrm{o}}(\mathrm{dia})$ & $t_{\mathrm{f}}($ dia $)$ & $\bar{t}$ (dia) \\
\hline Pirênios despolpados & $40,75 \mathrm{ab}$ & $62,25 \mathrm{a}$ & $49,78 \mathrm{a}$ \\
Despolpados e secos & $41,13 \mathrm{ab}$ & $61,75 \mathrm{a}$ & $49,90 \mathrm{a}$ \\
Despolpados, secos e escarificados & $40,25 \mathrm{ab}$ & $63,88 \mathrm{a}$ & $49,74 \mathrm{a}$ \\
Despolpados, secos, escarificados e embebidos em & $42,50 \mathrm{~b}$ & $68,25 \mathrm{a}$ & $51,72 \mathrm{a}$ \\
água por 6 horas & & & \\
Despolpados, secos, embebidos a $60^{\circ} \mathrm{C}$ por 5 minutos & $35,25 \mathrm{a}$ & $65,25 \mathrm{a}$ & $48,40 \mathrm{a}$ \\
e embebidos em água por 12 horas & 6,09 & 13,04 & 3,92 \\
\hline$D M S(0,05)$ & 10,5 & 13,98 & 5,41 \\
$C V(\%)$
\end{tabular}

Em que: Médias seguidas por letras distintas, nas colunas dentro de cada fator, diferem entre si pelo teste de Tukey a 0,05 de significância. ${ }^{1} t_{\mathrm{o}}=$ tempo inicial; $t_{\mathrm{f}}=$ tempo final; $\bar{t}=$ tempo médio de germinação. ${ }^{2}$ Nos tratamentos prégerminativos que envolveram pirênios secos, a secagem foi feita à temperatura ambiente $\left(25 \pm 1,5^{\circ} \mathrm{C}\right)$ sobre papel toalha por 12 horas e quando escarificados, este tratamento foi seguido de lavagem em água corrente por 12 horas. 
verde-arroxeados respectivamente indicaram baixa velocidade, ou seja, menos de um pirênio germinou por dia.

A variabilidade relativa ao tempo médio de germinação dos pirênios não revelou diferenças significativas quanto ao grau de maturação dos frutos, registrando $12,9 \%$ de variação para pirênios oriundos de frutos verde-arroxeados e 14,3\% para pirênios de frutos verdes (Tabela 3 ). $\mathrm{O}$ alto valor de incerteza para a germinação de pirênios de frutos verde-arroxeados $(I=3,12$ bit $)$ indicou que apesar da maior germinação dos pirênios neste grau de maturação, o processo foi incerto. Reforça essa característica, a baixa frequência de germinação num mesmo intervalo de tempo, indicada pelos baixos valores de sincronia, ainda que não significativos para os diferentes graus de maturação $(Z .=0,070$ e 0,071 para frutos verdes e vede-arroxeados, respectivamente).
Independente do estágio de maturação, quando os pirênios foram embebição a $60^{\circ} \mathrm{C}$ por 5 minutos e embebidos em água destilada à temperatura ambiente por 12 horas, depois de despolpados e secos, a germinação foi antecipada $\left(t_{0}\right.$ = 35 dias; Tabela 2), aumentando o número médio de pirênios por dia $\left(0,32\right.$ pirênio dia ${ }^{-1}$; Tabela 3$) \mathrm{em}$ relação a pirênios despolpados, secos, escarificados e embebidos em água por 6 horas.

Os percentuais de germinação não diferiram entre os tratamentos pré-germinativos aplicados aos pirênios, variando entre 48,5 e 59,5\% (Tabela 3). Valores referentes à germinação de pirênios de Schefflera morototoni são variáveis na literatura. Leão (1984) encontrou 48,5\% de germinação para sementes recém-colhidas; Carvalho (2003), 48\% na Região Sul e na Região Norte até $70 \%$, enquanto que Franco e Ferreira (2002), não obtiveram germinação para sementes recém-colhidas.

TABELA 3: Medidas de germinação de pirênios de Schefflera morototoni (Aubl.) Maguire, Steyerm. \& Frodin coletados em diferentes estádios de maturação em fragmentos florestais na bacia do Rio Araguari, $\mathrm{MG}$ e submetidos a tratamentos pré-germinativos ${ }^{(1)}$.

TABLE 3: Germination measurements of Schefflera morototoni (Aubl.) Maguire, Steyerm. \& Frodin pyrenes harvested in different stages of fruit maturation in forest fragments in the basin of Araguari River, MG and submitted to pre-germination treatments.

\begin{tabular}{|c|c|c|c|c|c|}
\hline Fatores & \multicolumn{5}{|c|}{ Medidas de germinação (unidade) } \\
\hline Estágio de maturação & $G(\%)$ & $V E\left(\right.$ pir. dia $\left.{ }^{-1}\right)$ & $C V_{\mathrm{t}}(\%)$ & $I$ (bit) & $Z$ \\
\hline Frutos verdes & $40,6 \mathrm{~b}$ & $0,20 \mathrm{~b}$ & $14,30 \mathrm{a}$ & $2,75 \mathrm{~b}$ & $0,070 \mathrm{a}$ \\
\hline Frutos verde-arroxeados & $62,8 \mathrm{a}$ & $0,33 \mathrm{a}$ & $12,92 \mathrm{a}$ & $3,12 \mathrm{a}$ & $0,071 \mathrm{a}$ \\
\hline$D M S(0,05)$ & 7,02 & 0,04 & 2,96 & 0,27 & 0,04 \\
\hline Tratamentos pré-germinativos ${ }^{1}$ & $G(\%)$ & $V E\left(\right.$ pir. dia $\left.{ }^{-1}\right)$ & $C V_{\mathrm{t}}(\%)$ & $I$ (bit) & $Z$ \\
\hline Pirênios despolpados & $48,5 \mathrm{a}$ & $0,25 \mathrm{ab}$ & $12,27 \mathrm{a}$ & $2,96 \mathrm{a}$ & $0,062 \mathrm{a}$ \\
\hline Despolpados e secos & $52,5 \mathrm{a}$ & $0,27 \mathrm{ab}$ & $11,90 \mathrm{a}$ & $2,88 \mathrm{a}$ & $0,080 \mathrm{a}$ \\
\hline Despolpados, secos e escarificados & $49,5 \mathrm{a}$ & $0,26 \mathrm{ab}$ & $13,55 \mathrm{a}$ & $2,80 \mathrm{a}$ & $0,079 \mathrm{a}$ \\
\hline $\begin{array}{l}\text { Despolpados, secos, escarificados e } \\
\text { embebidos em água por } 6 \text { horas }\end{array}$ & $48,5 \mathrm{a}$ & $0,24 \mathrm{~b}$ & $13,88 \mathrm{a}$ & $2,81 \mathrm{a}$ & $0,091 \mathrm{a}$ \\
\hline $\begin{array}{l}\text { Despolpados, secos, embebidos a } 60^{\circ} \mathrm{C} \\
\text { por } 5 \text { minutos e embebidos em água por } \\
12 \text { horas }\end{array}$ & 59,5 a & $0,32 \mathrm{a}$ & $16,46 \mathrm{a}$ & $3,21 \mathrm{a}$ & $0,042 \mathrm{a}$ \\
\hline$D M S(0,05)$ & 15,78 & 0,08 & 6,64 & 0,62 & 0,09 \\
\hline$C V(\%)$ & 21,03 & 20,64 & 33,64 & 14,47 & 83,38 \\
\hline
\end{tabular}

Em que: Médias seguidas por letras distintas, nas colunas dentro de cada fator, diferem entre si pelo teste de Tukey a 0,05 de significância. $G=$ porcentagem de germinação; $V E=$ velocidade de Maguire; $C V_{t}=$ coeficiente de variação do tempo; $I$ = incerteza; $Z$ = índice de sincronização. ${ }^{1}$ Nos tratamentos pré-germinativos que envolveram pirênios secos, a secagem foi feita à temperatura ambiente $\left(25 \pm 1,5^{\circ} \mathrm{C}\right)$ sobre papel toalha por 12 horas e quando escarificados, esse tratamento foi seguido de lavagem em água corrente por 12 horas.

Ci. Fl., v. 20, n. 3, jul.-set., 2010 
De acordo com Ohashi e Leão (2005), o tratamento pré-germinativo de imersão em água quente por 5 minutos, seguida da imersão em água à temperatura ambiente por 12 horas pode resultar em germinação superior a $70 \%$ entre 25 e 45 dias para as sementes de Schefflera morototoni. A eficácia da embebição em água aquecida pode estar relacionada a fissuras no tegumento (ALVES et al., 2004) ou amolecimento dos tecidos e aceleração das reações fisiológicas do tegumento das sementes, favorecendo a absorção de água, trocas gasosas e a germinação (MARTINS et al., 1997).

Liegel (1990) argumentou que, em Porto Rico, algumas aves se alimentam de Schefflera morototoni e esse fato pode contribuir para a germinação em campo. De acordo com Pooley (1993), sementes de Schefflera umbellifera Baill., quando consumidas por aves, germinam entre quatro e seis semanas, provavelmente o suco gástrico do sistema digestivo das aves auxilia na germinação.

Observou-se grande proliferação de fungos nos pirênios logo na primeira semana da instalação do experimento. Segundo Martins Netto e Faiad (1995), um dos fatores responsáveis pela deterioração das sementes de Schefflera morototoni e a baixa porcentagem de germinação, é a grande ocorrência de fungos patogênicos e saprófitos. Essa alta incidência de fungos pode ter ocorrido em função da não assepsia das sementes, mas cabe ressaltar que o endocarpo é permeável e o uso produtos químicos pode afetar a germinação.

A dispersão em torno do tempo, representada pelo coeficiente de variação do tempo $(C V)$, foi similar entre os tratamentos pré-germinativos, com valores entre 11,90 e $16,46 \%$ (Tabela 3 ), indicando que a germinação foi concentrada em torno do tempo médio de cada tratamento. Os valores de incerteza de 2,80 a 3,21 bits, juntamente com os de índice de sincronização baixos e próximos de zero (entre 0,042 e 0,091 ) inferem que a germinação é incerta e assíncrona ao longo do tempo, ou seja, baixa sobreposição de sementes germinadas num mesmo intervalo.

A germinação demorada e irregular da espécie pode, de acordo com Franco e Ferreira (2002), estar relacionada a algum tipo de inibidor de germinação no tegumento ou problema de maturidade do embrião. Um indicativo de dormência morfológica se deve ao fato do embrião ser diminuto e reto (OHASHI e LEÃO, 2005). Nesse tipo de dormência, a maior parte da semente é ocupada por endosperma e o embrião pode representar apenas
$1 \%$ do volume da semente, ou até menos, assim estas necessitam de mais tempo sob condições apropriadas para a germinação (NIKOLAEVA, 1977).

\section{CONCLUSÕES}

Para maior capacidade e velocidade de germinação dos pirênios, os frutos de Schefflera morototoni devem ser colhidos quando apresentarem coloração verde-arroxeada, descartando-se aqueles com pirênios chochos, endosperma retraído ou oxidado.

A capacidade de germinação dos pirênios com endosperma uniforme varia entre 50 e $60 \%$, com início do processo em cerca de 40 dias após semeadura, se estendendo por até 60 dias, em vermiculita.

Pirênios despolpados, secos e embebidos em água a $60^{\circ} \mathrm{C}$ por 5 minutos, seguido da embebição em água à temperatura ambiente por 12 horas iniciam o processo de germinação em menor tempo, em relação aos despolpados, secos, escarificados e embebidos por 6 horas.

O endocarpo dos frutos é permeável e rígido, no entanto, apresenta abertura natural quando embebido.

\section{AGRADECIMENTOS}

À Coordenação de Aperfeiçoamento de Pessoal de Nível Superior (CAPES), pela concessão da bolsa de mestrado da primeira autora; à Fundação de Amparo à Pesquisa do Estado de Minas Gerais (FAPEMIG) e ao Conselho Nacional de Desenvolvimento Científico e Tecnológico (CNPq) pelas bolsas de iniciação científica da terceira e quarta autoras.

\section{REFERÊNCIAS BIBLIOGRÁFICAS}

ALVES, A. U. et al. Superação da dormência em sementes de Bauhinia divaricata L. Acta Botanica Brasilica, São Paulo, v. 18, n. 4, p. 871-879, out./ dez. 2004.

ARMELIN, R. S. As dinâmicas de Schefflera angustissima (March.) Frodin (Araliaceae) e de Andira anthelmia (Vell.) March. (Fabaceae) na reserva e Morro Grande, São Paulo. 2005. 212 f. Tese (Doutorado em Ecologia) - Universidade de São Paulo, São Paulo, 2005.

BEWLEY, J. D.; BLACK, M. Seeds: physiology of 
Anastácio, M. R. et al.

development and germination. New York: Plenum Press, 1994. 455 p.

BRAGA, F. M. S.; REZENDE, A. V. Dinâmica da vegetação arbórea da mata de galeria do catetinho, Brasília- DF. Cerne, Lavras, v. 13, n. 2, p. 138-148, abr./jun. 2007.

CARVALHO, P. E. R. Espécies arbóreas brasileiras. Colombo: Embrapa Florestas, 2003. $1039 \mathrm{p}$.

FIASCHI, P. Schefflera aurata, a new species of Araliaceae from Southern Bahia (Brazil). Brittonia, New York, v. 56, n. 4, p. 357-360, Oct. 2004.

FIASCHI, P.; PIRANI, J. R. Estudo taxonômico do gênero Schefflera J.R. Forst. \& G. forst. (Araliaceae) na região Sudeste do Brasil. Boletim de Botânico da Universidade de São Paulo, São Paulo, v. 25, n. 1, p. 95-142, abr. 2007.

FRANCO, E. T. H.; FERREIRA, A. G. Tratamentos pré-germinativos em sementes de Didymopanax morototoni (Aubl.) Dcne. et Planch. Ciência Florestal, Santa Maria, v. 12, n. 1, p. 1-10, jun. 2002.

GIEHL, E. L. H.; BUDKE, J. C.; ATHAYDE, E. A. Distribuição espacial de espécies arbóreas em uma floresta estacional em Santa Maria, Sul do Brasil. Instituto Anchietano de Pesquisas, São Leopoldo, n. 58, p. 215-226, 2007.

LEÃO, N. V. M. Conservação de sementes de morototó (Didymopanax morototoni (Aublet.)) Decne. Belém: EMBRAPA-CPATU, 1984. 16 p.

LIEGEL, L. H. Didymopanax morototoni (Aubl.) Decne. \& Planch. (yagrumo macho). In: BURNS, R. M.; HONKALA, B. H. (Eds.). Silvics of North America. Washington: Forest Service, 1990. p. 288-293.

LIMA, S. do C.; QUEIROZ NETO, J. P. de; LEPCSH, I. F. Os solos da chapada Uberlândia Uberaba. In: LIMA, S. do C.; SANTOS, R. J. (Eds.). Gestão ambiental da bacia do Rio Araguari: rumo ao desenvolvimento sustentável. Uberlândia: EDUFU, 2004. p. 89-124.

LOPES, J. C. et al. Tratamentos para superar a dormência em sementes de arroz (Oryza sativa L.). Revista Brasileira de Sementes, Pelotas, v. 20, n. 1, p. 87-92, jan./abr. 1998.

MARTINS NETTO, D. A.; FAIAD, M. G. R. Viabilidade e sanidade de sementes de espécies florestais. Revista Brasileira de Sementes, Pelotas, v. 17, n. 1, p. 75-80, jan./mar. 1995.

MARTINS, C. C. et al. Superação da dormência de sementes de carrapicho-beiço-de-boi. Planta Daninha, Viçosa, v. 15, n. 2, p. 104-113, abr./jun.
1997.

MEDEIROS, A. C. de S.; SILVA, L. C. da. Efeitos da secagem na viabilidade das sementes de Ilex paraguariensis St. Hil. Boletim de Pesquisa Florestal, Colombo, n. 42, p. 35-46, jan./jun. 2001. MENEZES, C. et al. Competição entre abelhas durante forrageamento em Schefflera arboricola (Hayata) Merr. Bioscience Journal, Uberlândia, v. 23, p. 63-69, nov. 2007.

NAZÁRIO, P. Tratamentos pré-germinativos visando minimizar a dormência em sementes de tucumã (Astrocaryum aculeatum G. Mey.). 2006. 89 f. Dissertação (Mestrado em Ciências de Florestas Tropicais) - Instituto Nacional de Pesquisas da Amazônia, Manaus, 2006.

NIKOLAEVA, M. G. Factors controlling the seed dormancy pattern. In: KHAN, A. A. (Ed.). The physiology and biochemistry of seed dormancy and germination. Amsterdam: North-Holland, 1977. p. 51-74.

OHASHI, S. T.; LEÃO, N. V. M. Morototó Schefflera morototoni (Aubl.) Maguire, Steyern. \& Frodin. Informativo Técnico Rede de Sementes da Amazônia, n. 12, 2005. Disponível em: < (http:// www.rsa.ufam.edu.br:8080/sementes/especies/pdf/ doc12.pdf) > Acesso em: 25 de fevereiro de 2009.

POOLEY, E. The complete field guide to trees of Natal, Zululand, and Transkei. Durban: Natal Flora Publications Trust, 1993. 512 p.

RANAL, M. A.; SANTANA, D. G. How and why to measure the germination process? Revista Brasileira de Botânica, São Paulo, v. 29, n. 1, p. 1-11, jan./mar. 2006.

RIBEIRO, C. V. C.; KAPLAN, M. A. C. Tendências evolutivas de famílias produtoras de cumarinas em Angiospermae. Química Nova, São Paulo, v. 25, n. 4, p. 533-538, jul. 2002.

SILVA, J. A. et al. Caracterização florística, fitossociológica e regeneração natural do subbosque da reserva genética florestal Tamanduá, DF. Ciência Florestal, Santa Maria, v. 14, n. 1, p. 121132, dez. 2004.

SILVA, J. B.; VIEIRA, R. D.; CECÍLIO FILHO, A. B. Superação de dormência em sementes de beterraba por meio de imersão em água corrente. Horticultura Brasileira, Brasília, v. 23, n. 4, p. 990-992, out./dez. 2005.

TOKUHISA, D. et al. Compostos fenólicos inibidores da germinação em sementes de mamão (Carica papaya L.). Revista Brasileira de Sementes, Pelotas, v. 29, n. 3, p. 180-188, set./dez. 2007. 
VIEIRA, A. R. et al. Efeitos de tratamentos prégerminativos na superação da dormência de sementes de arroz e na atividade enzimática da peroxidase. Pesquisa Agropecuária Brasileira, Brasília, v. 29, n. 4, p. 535-542, abr. 1994.
WEN, J. et al. The Evolution of Araliaceae: a phylogenetic analysis based on its sequences of nuclear ribosomal DNA. Systematic Botany, Wyoming, v. 26, n. 1, p. 144-167, Jan. 2001. 